\title{
EFFECT OF BLAST-INDUCED COLUMN FAILURE PATTERN ON COLLAPSE BEHAVIOR OF STEEL FRAMES
}

\author{
G.Q. Li ${ }^{1,2}$, Y. Zhang ${ }^{2,3}$, T.C. Yang ${ }^{4}$, J. Jiang ${ }^{2, *}$, Y. Lu ${ }^{5}$ and S.W. Chen ${ }^{1,2}$ \\ ${ }^{1}$ State Key Laboratory for Disaster Reduction in Civil Engineering, Shanghai 200092, China; \\ ${ }^{2}$ College of Civil Engineering, Tongji University, Shanghai 200092, China; \\ ${ }^{3}$ Department of Building Engineering, Logistics University of PAPF, Tianjin 300309, China \\ ${ }^{4}$ School of Civil Engineering and Architecture, University of Jinan, Jinan 250022, China; \\ ${ }^{5}$ School of Engineering, the University of Edinburgh, Edinburgh EH9 3JF, United Kingdom \\ *(Corresponding author: E-mail: jiangjian_0131@163.com)
}

Received: 11 April 2017; Revised: 11 June 2017; Accepted: 22 July 2017

\begin{abstract}
This paper proposes two reduced-order modeling approaches (Equivalent spring model and Single degree of freedom model) to simplify the traditional dynamic analysis of a whole structure by two steps: (1) local damage analysis of columns under blast on a member level, and (2) global analysis with an equivalent spring model considering the failure process of damaged columns. This avoids the global structural analysis in Step 1 and also avoids the simulation of blast loads in Step 2. The failure time and residual load-bearing capacity of damaged columns under blast are considered and their effect on the global collapse resistance is studied. The results show that they have significant effect on the collapse resistance. The longer the failure time, the larger the residual resistance, the smaller the structural displacement, and the greater the collapse resistance. It is found that the dynamic behavior of structures is sensitive to the ratio of column failure time to the structural vibration period $t_{0} / T$. The larger the $t_{0} / T$, the smaller the dynamic amplification effect. It is suggested to consider a smaller dynamic amplification factor rather than 2 for $t_{0} / T>0.3$. For the selection of analysis methods for blast-induced collapse of structures, it is recommended to adopt the alternate path method for $t_{0} / T<0.2$, and static analyses for $t_{0} / T>3$. While for $0.2<t_{0} / T<3$, dynamic analyses considering the effect of failure time and residual resistance of damaged columns should be conducted.
\end{abstract}

Keywords: Progressive collapse, steel framed structure, blast, equivalent spring method, single degree of freedom model, failure time, residual load-bearing capacity

DOI: $10.18057 /$ IJASC.2018.14.3.4

\section{INTRODUCTION}

Since the collapse of the World Trade Centre Towers under terrorist attack on September 11, 2001, there have been considerable interests in understanding the mechanism of blast-induced progressive collapse of tall buildings. The term "progressive collapse" is defined as "the spread of an initial local failure eventually resulting in the collapse of an entire structure or a disproportionately large part of it" [1]. It is generally recognized that increasing robustness is the key to reduce the chance of progressive collapse of structures. However, specific methodologies and design guides for robustness of steel framed structures are lacking. This situation is inconsistent with the fact that steel structures have increasingly become the predominant structural form for high-rise building construction, where explosion and impact are the major forms of abnormal loads and the consequence of collapse is immense.

Since the loss of a column in a structure may trigger its progressive collapse, resistance of columns against blast loads are given growing attentions. Song et al. [2] and Izzuddin et al. [3] presented a developed method for integrated adaptive nonlinear analysis of steel frames subject to fire and explosion loading. Parametric studies were conducted on column and frame configurations subjected to blast. Liew and Chen $[4,5]$ studied the behavior of steel columns under various blast loads and boundary conditions. Yu and Liew [6,7] investigated the behavior of steel framed structures subjected 
to combined blast and fire loads. The methods for determining the blast load and finite element techniques were reviewed, and numerical analysis of a five-storey building under blast and fire conditions were carried out. The results showed that the blast-damaged structures possessed little fire resistance. Magallanes et al. [8] carried out a series of full-scale blast tests on steel wide-flange columns. The results showed that severe local column deformations that essentially "open up" the section were observed though global deformation was small. Turcic et al. [9] investigated the cause and influencing factors of the collapse of a long-span steel roof structure. Yu et al. [10] studied the influence of levels of structural idealization (assembled beam model, grillage model and frame model) on the progressive collapse of steel framed structures. The results showed that the dynamic response of floors had a significant effect on the structural robustness. Grillage models with a simplified assembly procedure was proposed and its performance was verified. Demonceau and Jaspart [11] experimentally simulated the column loss process in a composite structure. The development and effect of membrane forces on the behavior of beam-to-column connections were discussed. Wu et al. [12] studied the dynamic response and residual axial capacity of reinforced concrete columns subjected to blast loads. The influence of material strength, column detailing and blast loads on the residual axial capacity was investigated. Nethercot et al. [13] proposed quantitative measures to improve the robustness of steel and composite buildings, based on a number of parametric studies. Wang et al. [14] conducted finite element analysis of progressive collapse of transmission tower system. The mass of the elements was retained after their removal due to loss of strength. It was found that the ultimate strain and strain rate of material had significant effect on the collapse modes.

The assessment of collapse performance of structures and measures for mitigating progressive collapse can be found in various design codes [1, 15-17]. ASCE 7 [1] proposes two general approaches for reducing the possibility of progressive collapse: Direct Design and Indirect Design. The former includes the Alternate Path method which requires that a structure be capable of bridging over a missing structural element in the event of a localized damage, and the Specific Local Resistance method which requires a building to provide sufficient strength to resist a specific load. For the Indirect Design approach, the structural resistance of the progressive collapse is considered implicitly through the provision of minimum levels of strength, continuity and ductility, such as catenary action of the floor slab, redundant structural systems, etc. The Tie Force approach is usually applied which prescribes a tensile force capacity to the connections between principal elements of the structure with the intention of allowing the structure to transfer load from the damaged portion of the structure to the undamaged part. Furthermore, in Eurocode EN 1991-1-7 [16], high-rise buildings would be classified as Class 3 and a systematic risk assessment approach is necessary [18].

The alternate path method assumes that the column is removed immediately regardless of the magnitude and duration of blast loads. In practice, although the duration of explosion on structural members is very short (in a unit of millisecond), the duration of dynamic response of a member under explosion to failure may be longer depending on material properties and geometry dimensions. It is unreasonable to neglect the failure process of members in all cases. Furthermore, the damaged components may have some residual load-bearing capacity. The presence of the failure time and residual capacity of the damaged members may affect the resistance of the whole structure against progressive collapse. The proposed approach in this paper is to contribute to the resolution of these two issues.

This paper investigated the effect of the failure process of columns subjected to explosion on the collapse of steel framed structures. The traditional dynamic analysis of a whole structure was simplified by using equivalent spring model and single degree of freedom (SDOF) model. The development of these two models was first presented. The methods to determine the failure time and residual load-bearing capacity of the column under blast were proposed. The performance of these two models were verified against results from analysis of a whole frame. Parametric studied were 
carried out to investigate the influence of the failure time and residual capacity of damaged columns on the collapse resistance of structures. Finally, recommendations were proposed for the selection of dynamic amplification factors and analysis methods for the progressive collapse of steel framed structures.

\section{WHOLE FRAME MODEL}

To study the collapse behavior of structures under explosion, a 2D steel frame was modeled in finite element software LS-DYNA, as shown in Figure 1. The frame had six bays of $4.5 \mathrm{~m}$ and twelve storey of $3 \mathrm{~m}$. All connections are assumed rigid in this study, which is the common practice for steel frame buildings in seismic zones. All the steel beams and columns were taken as I-type members of $\mathrm{I} 400 \times 200 \times 8 \times 10 \mathrm{~mm}$ and $\mathrm{H} 500 \times 500 \times 12 \times 15 \mathrm{~mm}$, respectively. The four numbers represent the height of the section, the width of the flange, thickness of the web and flange, respectively. A uniformly distributed load of $q$ was imposed on all the beams, and a lateral blast load $p$ was applied on the middle column of the ground floor. The three-dimensional Hughes Liu beam element was used to model the steel columns and beams. This element had an integrated cross-section and the command *INTEGRATION_BEAM was used to define an I-shape section. The arrangement of the integration points was achieved by an integration refinement parameter $k$. A value of $k=2$ was taken in this study where 7 and 6 integration points were arranged for the flange and web, respectively. The Plastic Kinematic model was used for the stress-strain curve of steel, and the Cowper-Symonds model was used to consider the effect of strain rate. The elastic, bulk and shear modulus of steel were taken as $2.06 \times 10^{5} \mathrm{MPa}, 1.49 \times 10^{5} \mathrm{MPa}$ and $8.11 \times 10^{4} \mathrm{MPa}$, respectively. The yielding stress was $310 \mathrm{MPa}$. The hardening constant, T hardening exponent $(\beta)$, strain rate constant $(C)$ and strain rate exponent $(P)$ were taken as $31 \mathrm{MPa}, 1,40$ and 5, respectively. The numerical modeling in LS-DYNA had been extensively validated and verified against experimental and analytical results, respectively, as presented in the references [19-22].

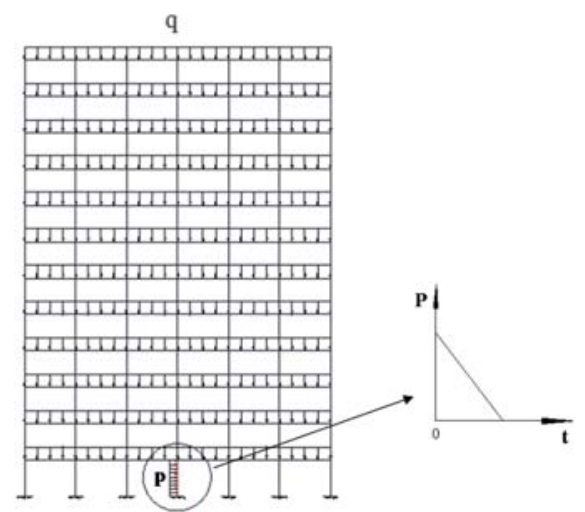

Figure 1. A 2D Steel Frame subjected to Blast Loads on a Ground Floor Column

Four cases of blast loads were considered in this study, as listed in Table 1. The overpressures of the blast loads were taken as $160 \mathrm{MPa}, 84 \mathrm{MPa}, 57 \mathrm{MPa}$ and $30 \mathrm{MPa}$, respectively. The equivalent linearly distributed load on the column were calculated by multiply the overpressure by the width of the column flange $(0.5 \mathrm{~m}$ in this case). It was assumed that the blast loads reduced linearly to zero in a duration of $0.8 \mathrm{~ms}, 1.2 \mathrm{~ms}, 1 \mathrm{~ms}$ and $1 \mathrm{~ms}$, respectively (Figure 1). Figure 2 shows the variation of the axial forces and mid-span displacement of the columns subjected to the first three blast loads. Due to a large blast load imposed in a short duration (Case 1), the blast load caused large lateral displacement of the column (Figure 2b), leading to decreasing compressive axial forces in it which even turned over to tensile forces as the frame did not response to this transient loading (Figure 2a). As running time increased, the response of the frame caught up with that of the column, and the column was 
subjected to compression again until its buckling. For the column subjected to a much smaller blast load (Case 3), the column did not fail after the blast but maintained a certain residual load-bearing capacity (Figure 2a). For the loading Case 2, the blast load caused large mid-span lateral displacements of the column (about $200 \mathrm{~mm}$ ), compared to that of about $30 \mathrm{~mm}$ for Case 3 . The large lateral mid-span displacement for Case 2 lead to the failure of the column, i.e. no residual loadbearing capacity.

Table 1. List of Loading Cases adopted in this Study

\begin{tabular}{cccccc}
\hline Case No. & $\begin{array}{c}\text { Blast pressure } \\
(\mathrm{MPa})\end{array}$ & $\begin{array}{c}\text { Specific } \\
\text { impulse } \\
(\mathrm{kPa} \cdot \mathrm{s})\end{array}$ & $\begin{array}{c}p \\
\left(10^{3} \mathrm{kN} / \mathrm{m}\right)\end{array}$ & $\begin{array}{c}\text { Time } \\
\text { duration } \\
(\mathrm{ms})\end{array}$ & $\begin{array}{c}q \\
(\mathrm{kN} / \mathrm{m})\end{array}$ \\
\hline 1 & 160 & 128 & 80 & 0.8 & 100 \\
2 & 84 & 101 & 42 & 1.2 & 100 \\
3 & 57 & 57 & 29 & 1 & 100 \\
4 & 30 & 30 & 15 & 1 & 75 \\
\hline
\end{tabular}

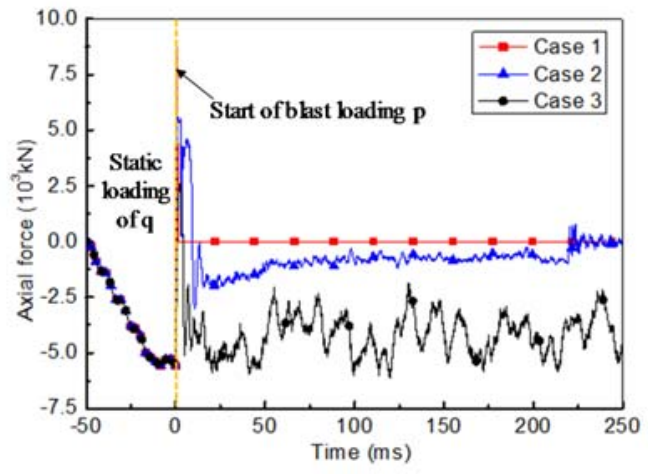

(a)

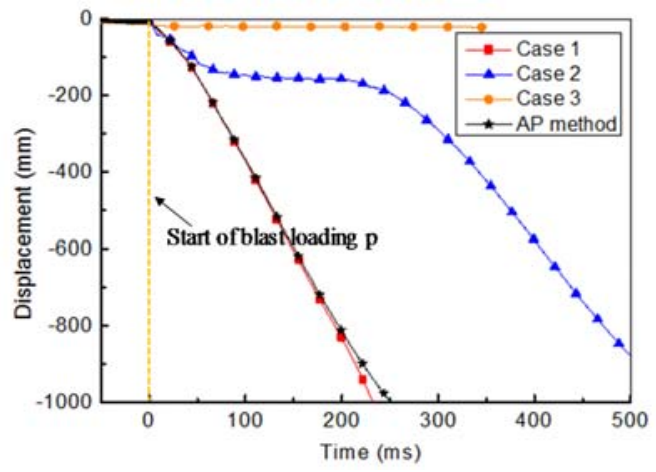

(b)

Figure 2. Variation of Responses in the Column subjected to Blast Loads:

(a) Axial Forces; (b) Mid-span Lateral Displacement

As shown in Figure 2b, the column mid-span displacement for Case 1 agreed well with those from Alternate Path (AP) method, while those for the other cases were quite different. In the alternate path method, a column is assumed to be removed immediately regardless of the magnitude and duration of blast loads. The vertical load $q$ is then amplified to some extent to consider the dynamic effect of the column removal. This method is applicable for unforeseeable explosion or impact loading conditions and is generally recognized to be conservative. In contrast, for an identified blast load imposed on the column, the axial force in the column may decrease from its initial value $N_{0}$ to $N^{\prime}$ as show in Figure 3. After the explosion, the frame will continue to deform under the vertical loads and thus the damaged column reaches its residual load-bearing capacity $N_{\mathrm{r}}[12,22,23]$.

In this case, the response of the column to failure $\left(t_{0}\right)$ during the explosion may be too long to be neglected depending on its material properties and geometry dimensions. Furthermore, there will exist some residual load-bearing capacity in the column after the explosion. The presence of the failure time and residual capacity of the damaged column will affect the resistance of the whole structure against progressive collapse. In this study the failure time to of the column under explosion was defined as the occurrence of the maximum lateral displacement at mid-span of the column. 


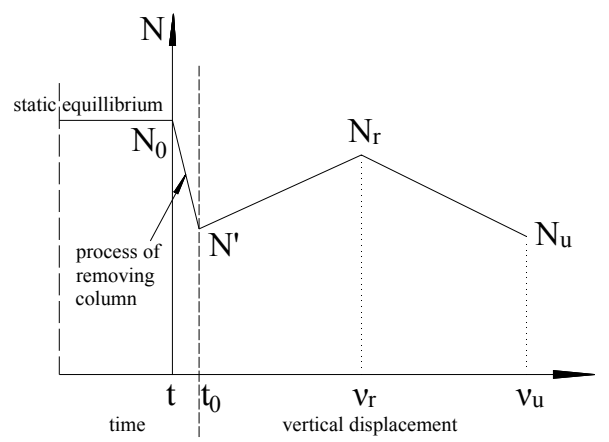

Figure 3. Variation of Axial Forces in a Column subjected to Blast Loads

Simplified models (Equivalent spring model and SDOF model) were proposed and presented in the following sections, to further investigate the effect of these two factors and also to simplify the analysis procedure of progressive collapse of structures.

\section{EQUIVALENT SPRING MODEL}

As an alternative to dynamic analysis of the whole structure, an equivalent spring method was proposed in this paper to simplify the analysis procedure, as illustrated in Figure 4. The development of the equivalent spring model is explained as follows: (1) Separate the column subjected to blast loads from the frame, and determine its failure time and residual load-bearing capacity on a member level, either analytically or numerically. This process will be demonstrated in more detail later; (2) Replace the damaged column by a spring model and apply a concentrated load on it, as shown in Figure 4a. The load has the same magnitude of the initial axial force in the column but opposite direction, i.e. the whole frame is still in equilibrium; (3) Change the magnitude of the load imposed on the spring according to Figure $4 \mathrm{~b}$ until the rebalance or collapse of the frame.

As shown in Figure $4 \mathrm{~b}$, it is assumed that the axial force in the damaged column reduces linearly from its initial value $N_{0}$ to its residual load-bearing capacity $N_{\mathrm{r}}$. After that, the axial resistance of the column is assumed to be constant (i.e. $N_{\mathrm{r}}$ ) until the rebalance or collapse of the frame. Note that the variation of axial forces in the damaged column in Figure $4 \mathrm{~b}$ was used in this study, to simplify the process shown in Figure 3. The proposed equivalent spring method took into account the dynamic effect of the column removal in terms of the column failure time to and the residual bearing capacity in terms of $N_{\text {r. }}$.

The proposed method divides the conventional complex analysis of steel frames against collapse into two independent steps: (1) Analysis of the local damage under explosion in a member-based level, i.e. analysis of the whole frame is avoided; (2) Analysis of the global behavior of the frame by considering the failure process of the damaged column, i.e. simulation of the blast load is avoided.

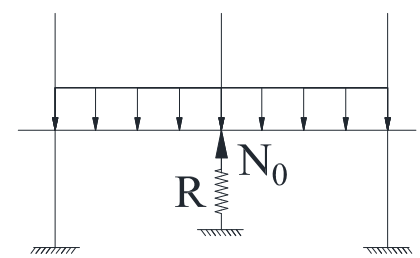

(a)

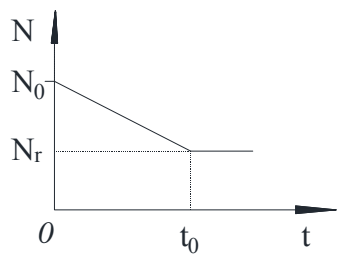

(b)

Figure 4. Schematic of Equivalent Spring Model: (a) Replacement of the Column with a Spring and Initial Axial Force in the Column; (b) Variation of the Axial Force during and after the Explosion 


\section{SDOF MODEL}

To further simplify the mechanism and assessment procedure of progressive collapse of steel frames, a single degree of freedom (SDOF) model was established, as shown in Figure 5. The middle column on the ground floor of the frame subjected to blast loads was replaced by a force $N_{0}$ with the same magnitude as the initial axial compression force in the column but in the opposite direction. Taking into account the restraint from surrounding bays, the frame above the damaged bay was simplified into a substructure with fixed end boundary conditions. The substructure was then reduced to a SDOF system with a mass of weight $m$ representing the whole substructure and a spring of stiffness $k$ equivalent to the vertical stiffness of the frame above the damaged column. When subjected to explosion, the column may experience large deformation. Thus, the axial displacement of the column reached its maximum value and its residual axial force reduced to $N_{\mathrm{r}}$. The failure process of the column under explosion can be characterized by the variation of the axial force in the column. There were mainly three models (A, B, C) for simulating the variation of axial forces in columns. The Model A represents the immediate removal of columns assumed in the alternate path method. The Models B and C consider the failure process of the column. It was assumed that the axial force in the column decreased linearly during the failure time $t_{0}$. The initial force in the column decreases to zero in the model B while a residual axial force $N_{\mathrm{r}}$ exists in the column after the blast loading for Model C.

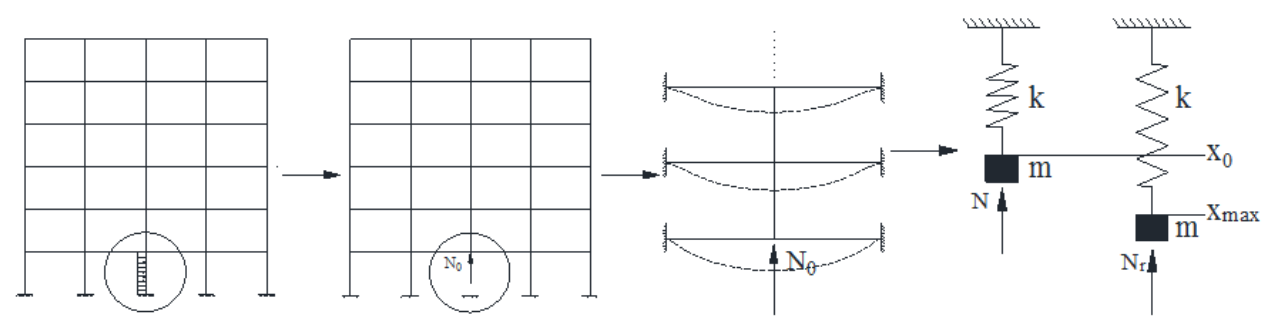

Figure 5. Schematic of SDOF model

In the SDOF model, the maximum displacement of the mass subjected to a blast load as in the Model A can be obtained simply through energy balance method. However, in the Models B and C, it is somewhat difficult to derive the analytical solution of the maximum response of the mass.

(1) In the model $\mathrm{A}$, the maximum displacement $x_{\max }$ of the mass is given as:

$x_{\max }=2 \cdot x_{s}=2 \cdot \frac{N_{0}}{k}$

where $x_{\mathrm{s}}$ is the static displacement of the mass in equilibrium under the force $N_{0} ; k$ is the stiffness of the spring.

From Equation 1, it can be seen that the maximum displacement $x_{\max }$ of the mass based on the alternate path method (Model A) is two times the corresponding static displacement $x_{\mathrm{s}}$. The consideration of the residual capacity $N_{\mathrm{r}}$ may result in a reduction in the displacement of the mass which is beneficial for mitigating progressive collapse of structures.

(2) The model $\mathrm{C}$ is considered to be the most practical case since it considers both the failure process and residual resistance of the column under explosion. When the deformation of the column follows the model $\mathrm{C}$, the displacement of the mass in the proposed SDOF system can be given as: 
$u=\left\{\begin{array}{lr}\left(\frac{N_{0}-N_{r}}{k}\right)\left[\left(\frac{t}{t_{0}}\right)-\left(\frac{1}{\omega \cdot t_{0}}\right) \sin \omega t\right] & \left(0 \leq t \leq t_{0}\right) \\ \left(\frac{N_{0}-N_{r}}{k}\right)\left\{1+\left(\frac{1}{\omega \cdot t_{0}}\right)\left[\sin \omega\left(t-t_{0}\right)-\sin \omega t\right]\right\} & \left(t>t_{0}\right)\end{array}\right.$

where $t_{0}$ is the failure time of the column under explosion; $\omega$ is the natural frequency of the SDOF system; $t$ is the time.

By defining $R$ as the dynamic amplification factor, Equation 2 can be transformed to:

$u=\left\{\begin{array}{lr}\left(\frac{N_{0}-N_{r}}{k}\right) R_{1} & \left(0 \leq t \leq t_{0}\right) \\ \left(\frac{N_{0}-N_{r}}{k}\right) R_{2} & \left(t>t_{0}\right)\end{array}\right.$

The displacement of the mass is expressed as the product of the static displacement (in the bracket) and dynamic amplification factor $R_{\mathrm{i}}$. The parameter $R$ depends on the frequency of the system and loading duration. The static displacement of the mass is given as:

$u_{s}=\frac{N_{0}-N_{r}}{k}=\frac{N_{0}}{k}-\frac{N_{r}}{k}$

According to Equation 4, the residual resistance $N_{\mathrm{r}}$ affects the static displacement directly. The greater the residual resistance, the smaller the displacement of the structure. The displacement is reduced by $\left(N_{\mathrm{r}} / k\right) R$ due to the presence of the residual resistance of the damaged column compared with the alternate path method. Therefore, the residual resistance in the column under blast actions has beneficial effects on arresting progressive collapse of structures.

As shown in Equation 2 and Figure 5, the axial displacement at the top of the column subjected to blast was affected by four key parameters $\left(k, m, t_{0}, N_{\mathrm{r}}\right)$. The determination of these four parameters will be presented in the following sections. The details of the deduction can refer to the reference [21].

\subsection{Determination of $k$ and $m$}

The axial displacement at the top of the ground column under blast is restrained by the frame above the column. The contribution of each storey to the restraining effect was not uniform along the height of the frame but reduced gradually from the second storey to the top of the frame. To consider the non-uniform distribution of vertical restraint, the frame above the column under blast was divided into two portions: the second storey just above the damaged column, and the frame from the third storey to the top, as shown in Figure 6. The spring stiffness and equivalent lumped mass of these two portions were defined as $k_{1}, m_{1}$ and $k_{2}, m_{2}$, respectively.

To further simplified this two-spring model to a single-spring model, the spring stiffness and mass of the model in Figure 5 can be calculated as $m=m_{1} \cdot \phi_{1}{ }^{2}+m_{2} \cdot \phi_{2}{ }^{2}, k=k_{1} \cdot\left(1-\phi_{2}\right)^{2}+k_{2} \cdot \phi_{2}{ }^{2}$ where the parameters $\phi_{1}, \phi_{2}$ are the displacement of the mass $m_{1}$ and $m_{2}$. 

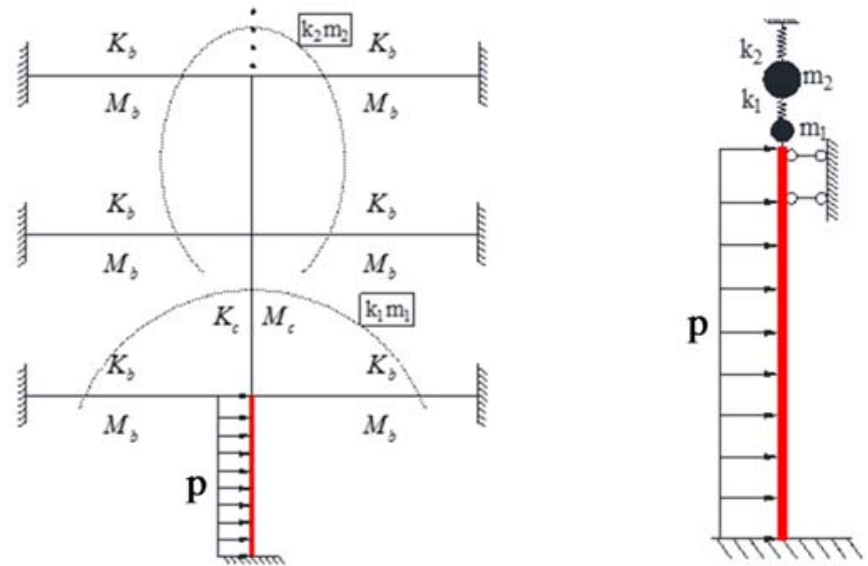

Figure 6. Schematic of Determination of $k$ and $m$

\subsection{Determination of Failure Time $t_{0}$}

The time to failure $t_{0}$ of a column under blast actions is defined as the occurrence of the maximum lateral displacement at its mid-span, as shown in Figure 4b. It was found that the failure time of an individual column with two ends fixed was similar to that resulting from the analysis on the whole frame [21]. This indicates that the boundary conditions of the column have litter effect on its lateral displacement. To this end, the failure time of a column fixed at its two ends was studied in this section. The failure time of a clamped column depends on such factors as the magnitude and duration of the blast action, the ultimate plastic moment of the column section, the vibration period of the column, etc. It is difficult to obtain the analytical solution of the failure time due to the large plastic deformation of steel columns under explosion. The clamped-clamped column can be simplified to a SDOF model. Under this condition, the failure time of the column can be solved simply based on the characteristics of SDOF system.

For the SDOF system, the blast load was assumed to be reduced linearly from $p_{0}$ to zero during a period of $t_{\mathrm{d}}$. The spring had an ideal elastic-plastic load-force curve. In the elastic and plastic phase, the motion equations of the SDOF model were expressed by Equation 5 and 6, respectively, as

$$
\begin{aligned}
& m \ddot{u}+k u=P_{(t)} \\
& m \ddot{u}+R=P_{(t)}
\end{aligned}
$$

where $m$ is the weight of the mass; $k$ is the stiffness of the spring; $R$ is the residual resistance of the spring; $P_{(\mathrm{t})}$ is the overpressure of the blast load at time $t$.

In the elastic state of the SDOF model, when $t<t_{\mathrm{d}}$, the displacement response of the mass can be written as:

$u_{(t)}=\left(\frac{p_{0}}{k}\right)\left[1-\left(\frac{t}{t_{d}}\right)-\cos \omega_{n} t+\left(\frac{1}{\omega_{n} \cdot t_{d}}\right) \sin \omega_{n} t\right]$

when $t>t_{\mathrm{d}}$, the displacement response of the mass is expressed as:

$u_{(t)}=\left(\frac{p_{0}}{k}\right)\left(\frac{1}{\omega_{n} \cdot t_{d}}\right)\left[\sin \omega_{n} t\left(1-\cos \omega_{n} t_{d}\right)-\cos \omega_{n} t\left(\omega_{n} t_{d}-\sin \omega_{n} t_{d}\right)\right]$

While in the plastic state, the displacement response is given as: 
$u_{2(t)}=\frac{1}{m}\left[\iint_{t^{\prime}} P_{(t)} d t d t-\frac{R\left(t-t^{\prime}\right)^{2}}{2}\right]+\dot{u}_{1\left(t^{\prime}\right)}\left(t-t^{\prime}\right)+u_{1\left(t^{\prime}\right)}$

where $t^{\prime}$ is the start time of the plastic state.

The determination of the dynamic response of the SDOF system above is still very complex because it needs to deal with the conversion process from elastic to plastic for ideal elasto-plastic resistance model. A simplification on it can resort to the numerical solution.

Given the relevant parameters of SDOF for the clamped-clamped column, the failure time of the column can be calculated easily using the exiting SDOF program.

Numerical analyses were conducted on the frame model (Figure 1) with the same geometry and loads as Case 4 in Table 1. Comparison of the mid-span lateral displacement of the damaged column between the frame model and SDOF model is shown in Figure 7. The parameters for the equivalent SDOF model were taken as $K=2.31 \times 10^{6} \mathrm{kN} / \mathrm{m}, \quad M=202 \mathrm{~kg}, P=28.8 \times 10^{6} \mathrm{kN}, R=7.82 \times 10^{6} \mathrm{kN}$. The maximum displacement and failure time of the column in the SDOF model agreed well with those from the frame model.

Given the material properties and geometry dimensions of the column under explosion, parameters for the equivalent SDOF model can be calculated and thus the failure time of the column can be determined based on the peak value and duration of blast loads. Figure 8 shows the relationship of the occurrence time of the system maximum displacement and the ratio of the column failure time to the system period for two peak blast loads of $P=28.8 \times 10^{6} \mathrm{kN}$ and $P=18.0 \times 10^{6} \mathrm{kN}$, respectively. The occurrence of the maximum system displacement was delayed as $t_{\mathrm{d}} / T$ increased.

The failure time of the column under blast actions can be determined based on the SDOF system with ideal elasto-plastic material. However, a numerical method should be taken to solve the equation. To further simplify the calculation, a rigid-plastic model was used for the stiffness of the spring in the SODF, thus the motion equation of SDOF can be expressed as:

$$
m \ddot{u}=P_{(t)}-R
$$

Substitution of the expression of $p_{(\mathrm{t})}$ into Equation 10 and through integration yields:

$$
m \dot{u}_{(t)}=p_{0}\left(t-\frac{t^{2}}{2 t_{d}}\right)-R t
$$

According to $\dot{u}_{(t)}=0$, the occurrence time $t_{\max }$ of the maximum displacement of the column, i.e. $t_{0}$ can be derived as:

$$
t_{0}=t_{\max }=2 t_{d}\left(1-\frac{R}{p_{0}}\right)
$$




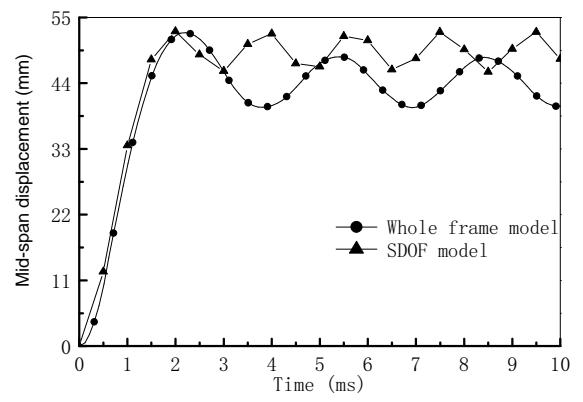

Figure 7. Comparison of the Lateral Displacement of the Column between Whole Steel Frame Model and Simplified SDOF System

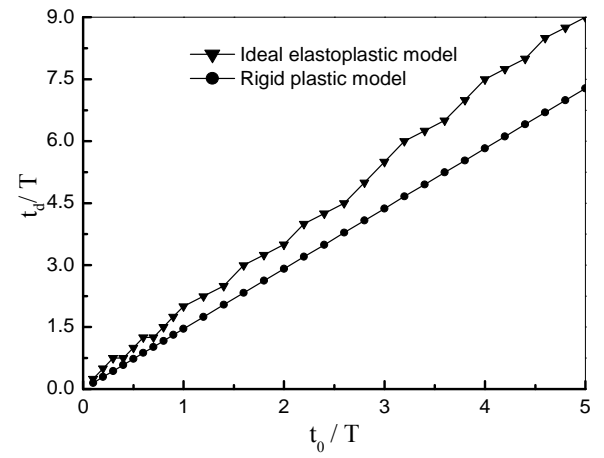

(a)

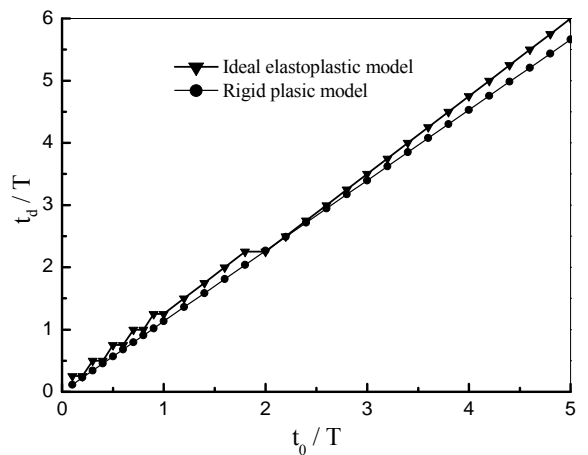

(b)

Figure 8. Variation of Occurrence Time of the Maximum Displacement Versus $t_{\mathrm{d}} / T$ for:

(a) $P=28.8 \times 10^{6} \mathrm{kN}$; (b) $P=18.0 \times 10^{6} \mathrm{Kn}$

The column failure time of the frame using rigid-plastic resistance model were compared with elastoplastic model in Figure 8 where reasonable agreement was obtained. Therefore, the rigid-plastic resistance model (Equation 12) can be used to reasonably predict the failure time of columns under explosion to facilitate the calculation.

\section{Determination of Residual Capacity $N_{\mathbf{r}}$}

Figure 9 illustrates the three steps to numerically determine the residual load-bearing capacity of columns. Firstly, the static equilibrium state is achieved for initial static loads. Secondly, based on the deformation and stress distribution of columns in the static equilibrium, the response of the column under blast loads is then solved. Finally, the residual load-bearing capacity $N_{\mathrm{r}}$ is obtained by displacement control method, i.e. gradually increase the vertical displacement of the top of the column until failure. The residual load-bearing capacity of the column depends on its initial static load, blast load and boundary conditions. Figure 10 shows the variation of axial forces in the column with the axial displacement of the column top for the Case 4 in Table 1.

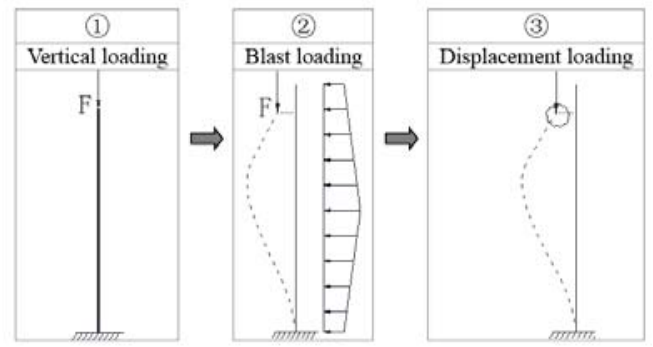

Figure 9. The Solution Process of the Residual Bearing Capacity of Columns using LS-DYNA 


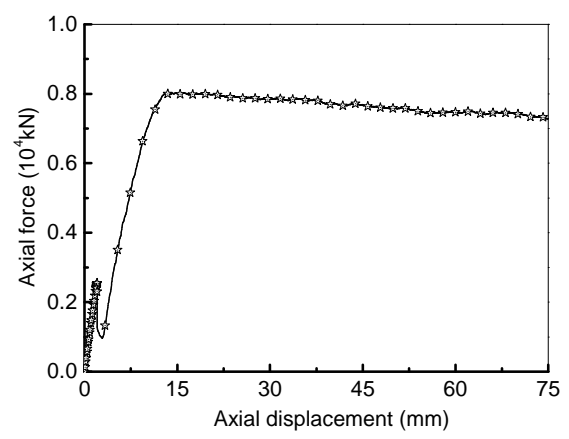

Figure 10. Variation of Axial Forces in the Damaged Column with Axial Displacement (Case 4 in Table 1)

\section{VERIFICATION OF SIMPLIFIED MODELS AND PARAMETRIC STUDY}

\subsection{Verification of Equivalent Spring Model}

The performance of the proposed spring models in Sections 3 and 4 was verified in this section by comparing with the results from whole frame model (Figure 1) and alternate path. The Case 3 and Case 4 in Table 1 were selected and the results are shown in Figure 11. The resistance of structures against progressive collapse was measured in terms of the axial displacement at the top of the column under explosion. The spring stiffness and mass in the SDOF model were calculated as $k=1.15 \times 10^{5} \mathrm{kN} / \mathrm{m}$ and $m=45.5 \times 10^{3} \mathrm{~kg}$, respectively. This led to a fundamental period of $T=125 \mathrm{~ms}$. According to Figure 10, the failure time and residual load-bearing capacity of the column were determined as $t_{0}=40 \mathrm{~ms}$ and $N_{\mathrm{r}}=3500 \mathrm{kN}$ for Case 3 , and $t_{0}=60 \mathrm{~ms}$ and $N_{\mathrm{r}}=8000 \mathrm{kN}$ for Case 4 . Figure 11 shows that due to the small static load and blast load, there was still some residual load-bearing capacity left in the column and no collapse of the frame occurred. The alternate path method overestimated the response of structures due to dynamic effects. The results from the whole frame model and proposed equivalent spring method were in a reasonable agreement.

The proposed equivalent spring method were used to study the influence of the failure time $t_{0}$ and residual bearing capacity $N_{\mathrm{r}}$ of the column under explosion on the axial displacement of the frame in Figure 1 as follows.

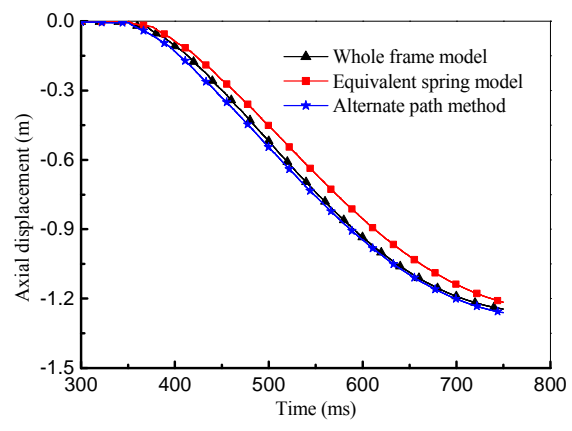

(a)

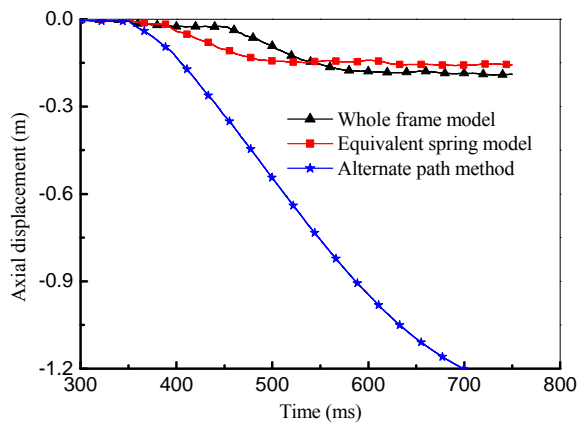

(b)

Figure 11. Comparison of Axial Displacement of the Columns Predicted from Different Modeling Approaches: (a) Loading Case 3 in Table 1; (b) Loading Case 4 in Table 1 


\subsection{Influence of Failure Time $t_{0}$}

The residual load-bearing capacity model $\left(N_{\mathrm{r}}=8000 \mathrm{kN}\right)$ of the column under explosion in Figure $4 \mathrm{~b}$ was used in this case. Five cases of failure duration of the column were adopted $(0 \mathrm{~ms}, 12 \mathrm{~ms}, 60 \mathrm{~ms}$, $120 \mathrm{~ms}$, infinity). Comparison of the axial displacement at the top of the column for the five failure cases is shown in Figure 12. The longer the failure time of the column, the smaller the displacement of the structure. When the failure time was infinite, the displacement is equivalent to the static response. Obvious dynamic effects were observed for an immediate removal $(0 \mathrm{~ms})$. The response for a removal of $12 \mathrm{~ms}$ almost coincided with the immediate removal. This indicates that only if the failure time is within certain range such as $60 \mathrm{~ms}$, it is necessary to consider the effect of the failure time of columns.

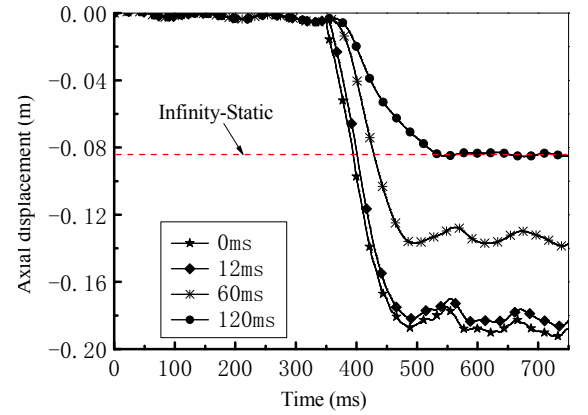

Figure 12. Comparison of Axial

Displacements of Columns for Different

Failure Times

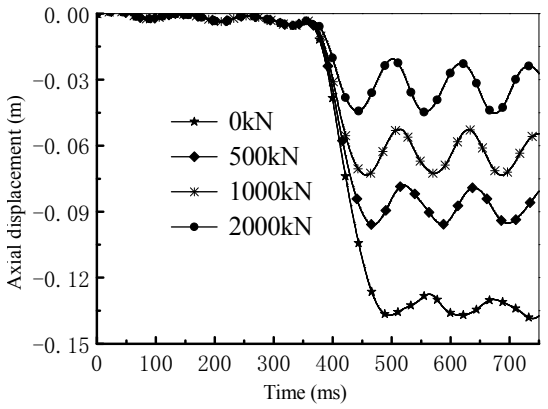

Figure 13. Comparison of Axial Displacements of Columns for Different Residual Load-bearing Capacity

\subsection{Influence of Residual Load-bearing Capacity $N_{\mathbf{r}}$}

The effect of the residual bearing capacity $N_{\mathrm{r}}$ of the damaged column on the progressive collapse of structures was studied herein. The same failure time of $60 \mathrm{~ms}$ was taken. Four conditions of residual load-bearing capacity $N_{\mathrm{r}}$ of the column were considered $(0 \mathrm{kN}, 500 \mathrm{kN}, 1000 \mathrm{kN}, 2000 \mathrm{kN})$.

Figure 13 shows the variation of the axial displacement of the column for the four residual capacity cases. It showed that the larger the residual bearing capacity of the column, the smaller the displacement of the structure given the same failure time. Therefore, the existence of the residual bearing capacity can enhance the resistance of structures against progressive collapse. Therefore, it is of importance to consider the residual bearing capacity of the damaged column under explosion in the assessment of progressive collapse of structures.

\section{APPLICATION OF SDOF MODEL IN THE DESIGN}

According to Equation 2, the variation of the dynamic amplification factor against time was plotted in Figure 14. Two cases with different ratios of the failure time to to the system period $T$ of 0.2 and 1.5 were compared. The results showed that when $t_{0}<T$ (e.g. $t_{0}=0.2 T$ ), the occurrence of the maximum response of the system greatly lagged behind the failure of the column. This can be attributed to the fact that the failure process of the column was so short that there was no time for the frame to react and thus the displacement at the early stage of loading was small. In this case, the loading played a role in the form of impulse which was then transferred into the initial velocity of the mass. In contrast, when $t_{0}>T$ (e.g. $t_{0}=1.5 T$ ), the displacement response of the frame reached its peak earlier than that for $t_{0}<T$, and the whole frame fluctuated about the center axis of the pseudostatic deflection curve. 


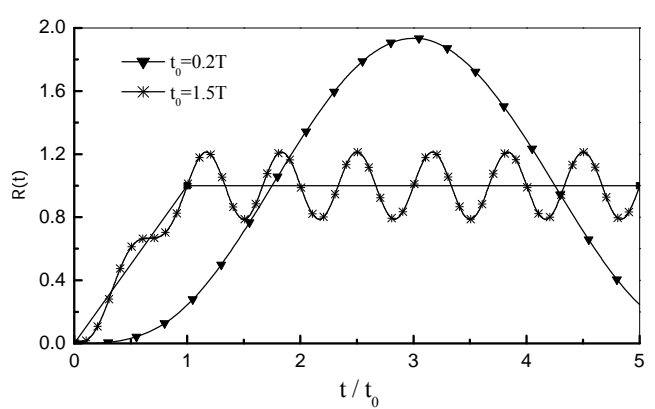

Figure 14. Variation of Dynamic Amplification Factors with the Ratio $t / t_{0}$

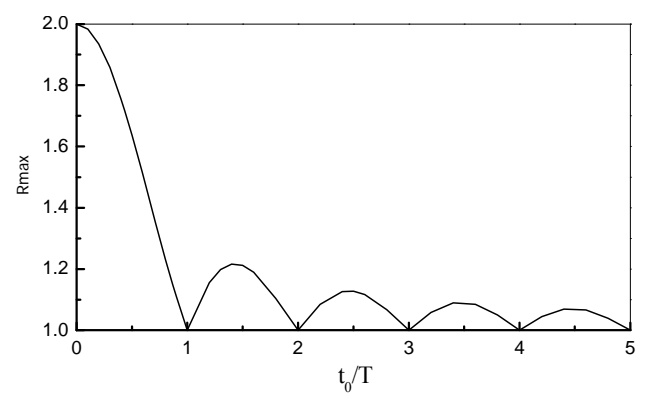

Figure 15. Variation of Dynamic Amplification Factors with the Ratio to/ $T$

Figure 15 shows the variation of dynamic amplification factors against the ratios of the failure duration $t_{0}$ to the system period $T$. The maximum dynamic amplification factor was 2 corresponding to the immediate column removal. It decreased with the increase of the ratio. For the ratios $\left(\tau=t_{0} / T\right)$ of $0.1,0.2$ and 0.3 , the dynamic amplification factors were $1.98,1.94$ and 1.86 respectively. For ratios greater than 3, the amplification factor is smaller than 1.1. To simplify the analysis of collapse of structures, it is suggested that the effect of the failure duration of the column on the dynamic response of structures can be neglected for $\tau<0.2$, i.e. alternate path method can be used. While for $\tau>3$, the failAure process of the structure is equivalent to static and thus its dynamic effect can be neglected, i.e. static analysis can be used. For $0.2<\tau<3$, the effect of failure process of the column under blast should be considered.

In a word, the failure process of the column under explosion should be considered in the assessment of progressive collapse of structures for $0.2<t_{0} / T<3$, while the alternate path method is available for $t_{0} / T<0.2$ and static analysis for $t_{0} / T>3$.

\section{CONCLUSIONS}

This paper proposed an equivalent spring model and SDOF model to simplify the analysis of progressive collapse of steel framed structures. The development and verification of these two models were presented. The influence of the failure time and residual load-bearing capacity of the column subjected to blast on the progressive collapse of structures was studied. The following conclusions can be drawn:

(1) The results from analysis of a whole frame under blast showed that the collapse resistance of the frame depended on the magnitude and duration of blast loads, which in turn affected the failure time and load-bearing capacity of the column subjected to blast. For a smaller blast load imposed in a relatively longer duration, there was some residual resistance in the damaged column which may enhance the resistance of the frame against blast-induced progressive collapse.

(2) The traditional dynamic analysis of progressive collapse of whole structures can be simplified by using an equivalent spring model. This includes two independent steps: (1) determine the failure process (failure time and residual load-bearing capacity) of the column under blast based on a member-level model; (2) replace the damaged column with an equivalent spring model considering the column failure process, and analyze the behavior of the remaining structure. The advantage of this simplification is to avoid the global structural analysis in Step 1 and also avoid the simulation of blast loads in Step 2. 
(3) A SDOF model was proposed to further simplify the analysis, and to analytically determine the failure time and residual load-bearing capacity of columns under blast. A rigid-plastic model was used instead of ideal elasto-plastic model to determine the failure time of columns.

(4) The failure time and residual resistance of the damaged column had significant effect on the collapse resistance of structures. The longer the failure time of the column, the larger the residual resistance, the smaller the displacement of the structure, and the greater its collapse resistance.

(5) It was found that the dynamic behavior of structures was sensitive to the ratio of column failure time to the structural vibration period $t_{0} / T$. The larger the $t_{0} / T$, the smaller the dynamic amplification effect. It was too conservative to use a dynamic amplification factor of 2 regardless of the failure process of the damaged column, since the factor reduced to 1.86 for $t_{0} / T=0.3$, and for $t_{0} / T>3$, the factor was smaller than 1.1.

(6) For the selection of analysis methods for the blast-induced progressive collapse of structures, it was suggested that alternate path method be used for $t_{0} / T<0.2$, and static analyses can be used for $t_{0} / T>3$. For $0.2<t_{0} / T<3$, the effect of failure time and residual resistance of damaged columns should be considered.

\section{ACKNOWLEDGMENTS}

The work presented in this paper was supported by the National Natural Science Foundation of China with grant 51120185001, 51408418, and 51508412. This work was also supported by Natural Science Foundation of Tianjin 16JCQNJC07000.

\section{REFERENCES}

[1] ASCE 7. American Society of Civil Engineers Standard 7 Minimum Design Loads for Buildings and Other Structures, American Society of Civil Engineers, 2010.

[2] Song, L., Izzuddin, B.A. and Elnashai, A.S., "Integrated Adaptive Environment for Fire and Explosion Analysis of Steel Frames - Part I: Analytical Models", Journal of Constructional Steel Research, 2000, Vol. 53, No. 1, pp. 63-85.

[3] Izzuddin, B.A., Song, L. and Elnashai, A.S., "Integrated Adaptive Environment for Fire and Explosion Analysis of Steel Frames - Part II: Verification and Application", Journal of Constructional Steel Research, 2000, Vol. 53, No. 1, pp. 87-111.

[4] Liew, J.Y.R. and Chen, H., "Explosion and Fire Analysis of Steel Frames using Fiber Element Approach", Journal of Structural Engineering, 2004, Vol. 130, No. 7, pp. 991-1000.

[5] Chen, H. and Liew, J.Y.R., "Explosion and Fire Analysis of Steel Frames using Mixed Element Approach", Journal of Engineering Mechanics, 2005, Vol. 131, No. 6, pp. 606-616.

[6] Yu, H.X. and Liew, J.Y.R., "Steel Framed Structures Subjected to the Combined Effects of Blast and Fire - Part 1: State-of-the-art Review", Advanced Steel Construction, 2005, Vol. 1, No. 1, pp. 67-84.

[7] Yu, H.X. and Liew, J.Y.R., "Steel Framed Structures subjected to the Combined Effects of Blast and Fire - Part 2: Case Study", Advanced Steel Construction, 2005, Vol. 1, No. 1, pp. 85-104.

[8] Magallanes, J.M., Martinez, R. and Koenig, J.W. "Experimental Results of the AISC Fullscale Column Blast Test”, Report. Karagozian \& Case, 2006.

[9] Turcic, F., Luketina, I. and Plisic, M., "Collapse and Rehabilitation of Steel Tanks Roof Structures”, Advanced Steel Construction, 2007, Vol. 3, No. 4, pp. 723-736. 
[10] Yu, H., Izzuddin, B.A. and Zha X.X., "Progressive Collapse of Steel-framed Buildings: Influence of Modelling Approach", Advanced Steel Construction, 2010, Vol. 6, No. 4, pp. 932-948.

[11] Demonceau, J.F. and Jaspart, J.P. "Experimental Test Simulating a Column Loss in a Composite Frame", Advanced Steel Construction, 2020, Vol. 6, No. 3, pp. 891-913.

[12] Wu, K., Li, B. and Tsai, K., "Residual Axial Compression Capacity of Localized Blastdamaged RC Columns", International Journal of Impact Engineering, 2011, Vol. 38, No. 1, pp. 29-40.

[13] Nethercot, D.A., Stylianidis, P., Izzuddin, B.A. and Elghazouli, A.Y. "Enhancing the Robustness of Steel and Composite Buildings", Advanced Steel Construction, 2011, Vol. 7, No. 1, pp. 64-85.

[14] Wang, W.M., Li, H.N. and Tian, L., "Progressive Collapse Analysis of Transmission Towerline System under Earthquake”, Advanced Steel Construction, 2013, Vol. 9, No. 2, pp. 161172.

[15] Design of Buildings to Resist Progressive Collapse, Unified Facilities Criteria (UFC) 4-02303, US Department of Defense (DoD), 2013.

[16] Eurocode 1: Actions on Structures - Part 1-7: General Actions -Accidental Actions, 2010.

[17] Progressive Collapse Analysis and Design Guidelines for New Federal Office Buildings and Major Modernization Projects, US General Services Administration (GSA), 2005.

[18] Manual for the Systematic Risk Assessment of High-risk Structures against Disproportionate Collapse. The Institute of Structural Engineers, UK, 2013.

[19] Li, G.Q., Sun, J.Y. and Wang, K.Q. "Research on a Simplified Frame Column Model to Resist Blast Load", Journal of Vibration and Shock, 2007, Vol. 26, No. 1, pp. 8-11.

[20] Sun, J.Y., "Study on the Behavior of Steel Reinforced Concrete Columns under Blast and Impact Loads", PhD thesis, Tongji University, Shanghai, China, 2006.

[21] Yang, T.C., "The Failure Mechanism of Steel Column under Blast Loading and its Effect on Progressive Collapse of Steel Frame”, PhD Thesis, Tongji University, Shanghai, China, 2013.

[22] Qu, H.Y., "Research on the Characteristics of Concrete-filled Steel Tubular Column Subjected to Blast Loading", PhD Thesis, Tongji University, Shanghai, China, 2011.

[23] Pilchard, S.J. and Perry, S.H., "The Impact Behavior of Sleeved Concrete Cylinders", The Structural Engineer, 2000, Vol. 178, No. 17, pp. 34-42. 